\title{
Prescribing Trends in the outpatient Department in A Rural Hospital in Bangladesh
}

\author{
Mizanur Rahman* and Saiful Islam \\ Department of Pharmacy, Daffodil International University, Bangladesh
}

Submission: July 05, 2019; Published: July 25, 2019

*Corresponding author: Mizanur Rahman, Department of Pharmacy, Daffodil International University, Dhaka, Bangladesh

Abstract

This study was carried out to find the medicine-prescribing pattern in outpatient department of Medicine, Surgery, Gynecology and Obstetrics in government and private hospitals in Faridpur city, Bangladesh. To see the patterns of prescriptions of 250 patients were collected over a period of three months and analyzed for the average number of drugs per prescription, number of drugs prescribed per prescription, most common diagnosis, most commonly prescribed antibiotics, most commonly prescribed groups of drugs, percentage of drugs prescribed by generic names, percentage of drugs prescribed from Essential Drug List (EDL) of Bangladesh. The average number of medicines per prescription was 4.14 and 48.8\% patients were prescribed up to 3 medicines. Only 37.I6\% drugs were prescribed from EDL of Bangladesh. Percentage of encounters with an antiulcer ant, a NSAID and a multivitamin \& mineral prescribed were $29.25 \%, 18.15 \%$ and $9.84 \%$ respectively.

It was evident that $73.6 \%$ [184] of the prescriptions contained antibiotics. Cefixim and ciprofloxacin were found to be the most preferred antibiotics in physician's prescriptions survey. The diseases, which were seen in the studies, include cough, typhoid, diarrhea, nausea, chronic UTI, RTI, fever and rhinitis. The result of the present survey indicates that antibiotics are widely and inappropriately practiced without following standard guidelines. This is an alarming condition in the health sector of Bangladesh and therefore, the respective authority should take necessary steps to minimize the harmful effects of antibiotics.

Keywords: Prescribing pattern; Essential drug; Antibiotic; Faridpur city; Rational use of drug

\section{Introduction}

Knowledge of risk perceptions has demonstrated to be vitally important in understanding how individuals and societies manage the risks of daily life. In medicine perceptions of drug risks are probably to influence patients' treatment decisions, their compliance with treatment regimens, their views on the acceptability of adverse reactions and the drugs that cause them, and their attitudes toward government regulation of medications. Understanding perceptions is a prerequisite for designing better communication materials for patients and the general population [1]. The drug use process can be separated into four fundamental components, namely: prescribing, dispensing, administration/ uptake and outcome (efficacy/safety) [2]. The evaluation of medication use is vital for clinical, educational and economic purposes [3]. Monitoring of prescriptions and drug utilization study could distinguish the related problems and give feed backs to the prescriber in order to make awareness for the rational use of drugs [4]. It is therefore necessary to define the prescribing pattern and target the irrational prescribing habit for sending a remedial message [5]. Therefore, the present study has been undertaken to observe the prescribing patterns of Antibiotics and the usage of these agents in different types of patients with different types of diseases in Faridpur City of Bangladesh.

\section{Materials and Methods}

Study area, duration of research project and data collection process. A cross-sectional study was conducted in order to evaluate prescription pattern of antibiotic drugs in patients with various infectious diseases. On the basis of inclusion and exclusion criteria prescriptions were collected from all patients (both male and female) attended the outpatient (OPD) at government and private hospitals in Faridpur city. The study was carried out over 90 days period of April 15th, 2018 to July 15th, 2018. A total of 250 patients were included in the study. New patients attending the outpatient department of Medicine, Surgery and Gynecology and Obstetrics in government and private hospitals in Faridpur city during the study period were considered for analysis. Follow up visits during the study period were included and were counted as separate visits. Patients visiting the emergency department or who got admitted during OPD visit 
were not included in the study. The average number of drugs per prescription, number of drugs prescribed per prescription, most common diagnosis, most commonly prescribed antibiotics, most commonly prescribed groups of drugs, percentage of drugs prescribed by generic names, Percentage of prescriptions with injectable preparations., percentage of drugs prescribed from Essential Drug List (EDL) of Bangladesh, The data was expressed as percentage, mean and total numbers.

\section{Results}

Table 1: Characteristics, frequency and percentage of patient's variables.

\begin{tabular}{|c|c|c|c|}
\hline Variables & Characteristics & Frequency (N) & Percentage (\%) \\
\hline \multirow{3}{*}{ Age } & $\leq 17$ years & 43 & 17.2 \\
\cline { 2 - 4 } & $18-50$ years & 37 & 14.8 \\
\cline { 2 - 4 } & $>50$ years & 170 & 68 \\
\hline \multirow{2}{*}{ Gender } & Male & 157 & 62.8 \\
\cline { 2 - 4 } & Female & 93 & 37.2 \\
\hline
\end{tabular}

Total number of 250 medical case records were collected, scrutinized and analyzed for drug prescription. The majority of the patients were male 157 (62.80\%) and 93 (37.2\%) patients

Table 3: Number of drugs prescribed per prescription.

\begin{tabular}{|c|c|c|c|c|c|c|c|}
\hline \multirow{2}{*}{$\begin{array}{c}\text { Prescription } \\
\text { Containing Number } \\
\text { of Drugs }\end{array}$} & \multirow{2}{*}{$\begin{array}{c}\text { Number of } \\
\text { Prescriptions }\end{array}$} & \multirow{2}{*}{$\%$} & \multirow{2}{*}{$\begin{array}{l}\text { Total number } \\
\text { of Drugs }\end{array}$} & \multirow{2}{*}{$\begin{array}{c}\text { Average Number } \\
\text { of Drugs Per } \\
\text { Prescription }\end{array}$} & \multicolumn{3}{|c|}{$\%$ of drugs Prescribed with } \\
\hline & & & & & Generic Name & Antibiotics & Injectable \\
\hline One & 6 & 2.4 & \multirow{7}{*}{1036} & \multirow{7}{*}{4.14} & \multirow{7}{*}{$\begin{array}{c}1.93 \%[20 \\
\text { drugs] }\end{array}$} & \multirow{7}{*}{$\begin{array}{c}28.08 \%[291 \\
\text { drugs] }\end{array}$} & \multirow{7}{*}{$\begin{array}{l}2.32 \%[24 \\
\text { drugs] }\end{array}$} \\
\hline Two & 42 & 16.8 & & & & & \\
\hline Three & 122 & 48.8 & & & & & \\
\hline Four & 69 & 27.6 & & & & & \\
\hline Five & 6 & 2.4 & & & & & \\
\hline Six & 3 & 1.2 & & & & & \\
\hline Seven & 2 & 0.8 & & & & & \\
\hline
\end{tabular}

Total number of drugs in our prescription was 1036. Among these, the most prescribed drugs were of acid related preparations (29.25\%). Then the second most prescribed drugs were antibiotics (28.09\%) Table 4.

Table 4: Most commonly prescribed groups of drugs.

\begin{tabular}{|c|c|c|}
\hline Diagnosis & Number of drugs $\mathbf{N}=\mathbf{1 0 3 6}$ & (\%) \\
\hline Antiulcerants & 303 & 29.25 \\
\hline NSAIDs & 188 & 18.15 \\
\hline Antibiotics & 291 & 28.09 \\
\hline $\begin{array}{c}\text { Multivitamins \& } \\
\text { multiminerals }\end{array}$ & 102 & 9.84 \\
\hline Antihistamines & 52 & 5.02 \\
\hline
\end{tabular}

At least one antibiotic was prescribed in 184 (73.6\%) of the 250 encounters and 77 prescription contain single antibiotic with other drugs. The most prescribed antibiotic was of cefixime 67 (23.02\%). Then the second most prescribed antibiotics ciprofloxacin (17.87\%) Table 5. were female with $14.80 \%$ of them aged between $18-50$ years Table 1.

Among 250 patients, we found that majority of the patients were victim of gastrointestinal tract infection (51.2\%). Other patients suffered from orthopedic disorder $(26.0 \%)$, respiratory tract infection $(8.0 \%)$, ENT infections $(8.0 \%)$ and urinary tract infection (6.8\%) respectively. These data are shown in Table 2.

Table 2: Most common diagnosis outpatients.

\begin{tabular}{|c|c|c|}
\hline Diagnosis & Number of cases $\mathbf{N = 2 5 0}$ & (\%) \\
\hline Gastroenterology & 128 & 51.2 \\
\hline Orthopedic disorder & 65 & 26 \\
\hline Respiratory tract infection & 20 & 8 \\
\hline ENT infections & 20 & 8 \\
\hline Urinary tract infection & 17 & 6.8 \\
\hline
\end{tabular}

In this research project, A total of 1036 individual drugs were prescribed for 250 drug encounters, giving an average of 4.14 . The range of drugs per encounter varied from 1-7. There was not a single prescription wherein no drug was prescribed. Moreover, very few drugs were prescribed by generic name (1.93\%). These data are represented in Table 3.

Table 5: Most commonly prescribed antibiotic.

\begin{tabular}{|c|c|c|}
\hline $\begin{array}{c}\text { Generic name of } \\
\text { Antibiotic }\end{array}$ & $\begin{array}{c}\text { Total Number of } \\
\text { antibiotic N=291 }\end{array}$ & Percentage (\%) \\
\hline Cefixime & 67 & 23.02 \\
\hline Ciprofloxacin & 52 & 17.87 \\
\hline Cefuroxime & 48 & 16.49 \\
\hline Levofloxacin & 34 & 11.68 \\
\hline Flucloxacillin & 28 & 9.62 \\
\hline Amoxicillin & 23 & 13.4 \\
\hline Others & 39 & \\
\hline
\end{tabular}

Among 1036 drugs only twenty drugs (1.93\%) were prescribed by generic names. It was also seen that out of 250 prescriptions only 385 drugs (37.16\%) were prescribed from the EDL of Bangladesh Table 6. 
Table 6: Drugs prescribed from EDL of Bangladesh.

\begin{tabular}{|c|c|c|}
\hline Drugs & Total number of drugs N=1036 & (\%) \\
\hline Included within EDL & 385 & 37.16 \\
\hline Excluded from EDL & 651 & 62.83 \\
\hline
\end{tabular}

The present study also shown that omeprazole 58\% and multivitamin with mineral $52 \%$ were prescribed among essential and non-essential drugs. The five most commonly prescribed drugs, which were included within or excluded from the EDL [6] of Bangladesh Table 7.

Table 7: Five most commonly prescribed drugs, which were included within or excluded from the EDL of Bangladesh.

\begin{tabular}{|c|c|c|}
\hline Drugs & Number of prescriptions & (\%) \\
\hline \multicolumn{2}{|c|}{ Included within EDL } \\
\hline Omeprazole & 145 & $58.00 \%$ \\
\hline Paracetamol & 120 & $48.00 \%$ \\
\hline Ferrous salt + Folic acid & 75 & $30.00 \%$ \\
\hline Metronidazole & 65 & $26.00 \%$ \\
\hline Ciprofloxacin & 52 & $20.80 \%$ \\
\hline \multicolumn{2}{|c|}{ Excluded within EDL } \\
\hline Multivitamin with mineral & 102 & $40.80 \%$ \\
\hline Ranitidine HCl & 85 & $34.00 \%$ \\
\hline Cetirizine HCl & 83 & $33.20 \%$ \\
\hline Calcium carbonate & 69 & $27.60 \%$ \\
\hline Cefixime & 67 & $26.80 \%$ \\
\hline
\end{tabular}

\section{Discussion}

A prescription that is given by a doctor or physician is taken as an indication of the doctor or physician's attitude towards the disease and the role of drugs in its treatment [7]. The central priority of health care system is providing the right medicine to the right people at the right time [8]. The source of data in these study 250 medical cases was collected and the percentages of male and female patients were $62.80 \%$ and $37.20 \%$. Most of the patients were above 50 years old. Similar results were obtained from the previous study, which was conducted by Khan et al. [9]. This prospective study was conducted on 4800 patients who visited the OPD and IPD of ENT department of Teerthanker Mahaveer Medical Hospital and Research Centre of North India. Their result indicated that higher percentage of male person suffering from different infections.

We observed that in the data of this research project, most of the patients were suffering from gastrointestinal disorders $(51.20 \%)$ and orthopedic disorder $(26.00 \%)$. It is important to note that drugs should be prescribed in their generic names to avoid confusion. In this study the average number of prescribed drugs were 4.14 and drugs were prescribed by generic name is $1.93 \%$. It also showed that $80.08 \%$ patients were given three or more drugs. The variation in results may be due to difference in characteristics of health care delivery system, morbidity and mortality characteristics in the population. Since, WHO has recommended that average number of drugs per prescription should be 2.0 [10], the results of the study reflect polypharmacy which may lead to adverse drug reactions, increase the risk of drug interactions, dispensing errors, decrease adherence to drug regimens and unnecessary drug expenses.

Antiulcerant drugs, 207 prescriptions (69\%) were found and the omeprazole [148 prescriptions (49\%)] was the most commonly prescribed of this class. The present observation remarked that $73.60 \%$ prescription contained antibiotic drugs along with other drugs. Among $41.85 \%$ prescription contained single antibiotic drug and $58.15 \%$ contained two antibiotic drugs. No prescription contained more than two antibiotic drugs. Prescriptions among which antibiotics that lie under Cefixime, Ciprofloxacin were most commonly prescribed. Similar results were obtained from the previous study, in Iran (61.9\%) [11]. In another study by Biswas et al revealed that mostly prescribed drugs were also antibiotics (49.22\%) [12]. According to WHO $15-25 \%$ of prescriptions with antibiotics are expected, where infectious diseases are more prevalent [13]. In a 3rd world developing country like Bangladesh, prevalence of infectious diseases is higher than the developed countries. That is why; in this study the antibiotic utilization rate was higher than that of developed countries. However, this result does not indicate that the prescription pattern was better than in other countries.

The WHO recommended target for injection exposure is $10 \%$ or less [14]. In this study, the percentage of prescription with an injection encountered was $2.32 \%$ which is less than in Nepal (3.1\%) [15], Zimbabwe (13\%) [16] and India (13.6\%) [17]. so, the observed proportion of injectable drugs prescribed may be considered acceptable according to WHO recommendations. Minimum use of injections is preferred, and this reduces the risk of infection through parenteral route and cost incurred in therapy [15]. It also showed that out of 250 prescriptions 102 (40.80\%) had at least one multivitamin and multimineral prescribed which was not enlisted in EDL. The justification for this practice is not clear. However, some patients and doctors believe that the multivitamin supplement may induce or enhance the patient's appetite or relief from weakness. In this study, the percentage of drugs prescribed from EDL of Bangladesh was $43.16 \%$. The possible reason for this lower value could be the prescribers lacking the understanding the importance of essential drug concept. The low rate of prescribing from EDL of Bangladesh may be also contributed by excessive use of multivitamin and multiminera, antiulcerant (Ranitidine) and antihistamine [Cetirizine $\mathrm{HCl}$ ], which are not enlisted in EDL of Bangladesh. So that the higher percentage of non-essential drugs in this study is responsible for inappropriate use of medicines.

\section{Conclusion}

Physician is often considered to be God and therefore when a doctor gives an antibiotic to a patient, it is taken without question. 
However, a doctor is often pressurized to give antibiotics for a variety of reasons. It could be due to the pressure of making a patient well as soon as possible, or the fear of losing patients to another doctor. Patients often demand powerful treatments, and then there is the industry pressure and incentive schemes, and, most importantly, the doctor's own clinical judgment skills. To be fair, many doctors work with inadequate and unreliable investigational facilities. This may promote the use of combination antibiotics and defensive medicine. From the result of this study, it can be concluded that inappropriate drug prescribing, inappropriate use of drugs and irrational prescribing of antibiotic are major problems. Therefore, there is a need strict enforcement and adherence to existing regulations regarding antibiotic practices. To overcome these problems, the drugs control authorities should be better equipped and more vigilant to cope with the present situation. Health professionals and drug manufacturers should be more committed in order to achieve the goals of the National Drug Policy of Bangladesh.

\section{References}

1. Paul Slovic, Nancy Kraus, Henner Lappe, Marilyn Major (1991) Risk Perception of Prescription Drugs: Report on a Survey in Canada. Canadian Journal of Public Health 82(3): S15-S20.

2. MSH (Management Science for Health) Managing for rational drug use $2^{\text {nd }}($ edn.): Pp. 422.

3. Uppal R, Nayak P, Sharma PL (1984) Prescribing trends in internal medicine. Int J Clin Pharm Ther Taxical 22: 373-376.

4. Pradhan SC, Shewade DG, Shashindran CH, Bapna JS (1988) Drug utilisation studies. National Med J India. Pp. 185-189

5. Mashford ML (1988) Update Victorian Medical Postgraduate Foundation Group. Aust J Hasp Pharm 18: 17-18.

6. Essential Drug List, Ministry of Health \& Family Welfare, Bangladesh Gazette.
7. Yadav P, Kanase V, Lacchiramka P, Jain S (2010) Drug utilization trends in ENT outpatient department in a Teaching hospital. Int J Pharm Biol Sci 1: 153-160.

8. Pallavi I, Shrivastava R, Sharma A, Singh P (2016) Prescribe Pattern of Drugs and Antimicrobials Preferences in the Department of ENT at Tertiary Care SGM Hospital, Rewa, MP, India. Journal of Pharmaceutical and Biomedical Sciences 6(2): 89-93.

9. Khan FA, Nizamuddin S, Salman MT (2011) Patterns of prescription of antimicrobial agents in the Department of Otorhinolaryngology in a tertiary care teaching hospital. African Journal of Pharmacy and Pharmacology 5(14): 1732-1738.

10. Sharif SI, Al Shaqra M, Hajjar H, Shamout A, Wess L (2007) Patterns of Drug Prescribing in a Hospital in Dubai, United Arab Emirates. Libyan J Med 3(1):10-12.

11. Moghadamnia AA, Mirbolooki MR, Aghili MB (2002) General practitioner prescribing patterns in Babol city, Islamic Republic of Iran. East Mediterr Health J 8(4-5): 550-555.

12. Biswas M, Roy DN, Islam M (2014) Prevalence and Nature of Handwritten Outpatients prescription errors in Bangladesh. Int J Pharm Pharm Sci 6(5): 126-130.

13. Lamichhane DC, Giri BR, Pathak OK, Panta OB, Shankar PR (2006) Morbidity profile and prescribing patterns among outpatients in a teaching hospital in Western Nepal. McGill J Med 9(2): 126-133.

14. World Health Organization (WHO). International Network for Rational Use of Drugs and World Health Organization. How to investigate drug use in health facilities: Selected drug use indicators 1993.

15. Ghimire S, Nepal S, Bhandari S, Nepal P, Palaian S (2009) A prospective surveillance of drug prescribing and dispensing in a teaching hospital in Western Nepal. J Pak Med Assoc 59(10): 726-731.

16. Lessing C, Trap B (1995) Zimbabwe Essential Drugs Action Programme (ZEDAP). Ministry of Health and Child Welfare Directorate of Pharmacy

17. Bhartiy SS, Shinde M, Nandeshwar S, Tiwari SC (2008) Pattern of prescribing practices in the Madhya Pradesh, India. Kathmandu Univ Med J 6(1): 55-59.

\section{Your next submission with Juniper Publishers} will reach you the below assets

- Quality Editorial service

- Swift Peer Review

- Reprints availability

- E-prints Service

- Manuscript Podcast for convenient understanding

- Global attainment for your research

- Manuscript accessibility in different formats

( Pdf, E-pub, Full Text, Audio)

- Unceasing customer service

Track the below URL for one-step submission https://juniperpublishers.com/online-submission.php 